\title{
Organochlorine pesticides (DDTs and HCHs) in soils from the outskirts of Beijing, China
}

\author{
Youfeng Zhu ${ }^{\text {a }}$, Hui Liu ${ }^{\text {a }}$, Zhiqun Xi ${ }^{\text {a }}$, Hangxing Cheng ${ }^{\mathrm{b}}$, Xiaobai Xu ${ }^{\mathrm{a}, *}$ \\ ${ }^{a}$ Research Center for Eco-Environmental Sciences, Chinese Academy of Sciences, Beijing 100085, People's Republic of China \\ ${ }^{\mathrm{b}}$ Institute of Geochemical and Geophysical Exploration, Beijing 065000, People's Republic of China
}

\begin{abstract}
Concentrations of $\mathrm{HCH}$ (hexachlorocyclohexane) and DDT (Dichlorodiphenyltrichloroethane) were determined in shallow subsurface (5-30 cm depth) and deep soil layers (150-180 cm depth) from the outskirts of Beijing, China. Concentrations of total HCHs (including $\alpha, \beta, \gamma, \delta$-isomers) and total DDTs (including $p, p^{\prime}$-DDT, $p, p^{\prime}$-DDE, $p, p^{\prime}$-DDD, $o, p^{\prime}$-DDT) in shallow subsurface soils ranged from 1.36 to $56.61 \mathrm{ng} / \mathrm{g} \mathrm{dw}$ (median $5.25 \mathrm{ng} / \mathrm{g}$ ), and from 0.77 to $2178 \mathrm{ng} / \mathrm{g}$ (median $38.66 \mathrm{ng} / \mathrm{g}$ ), respectively, and those in the deeper layers were approximately an order of magnitude less. The spatial distribution of HCHs and DDTs reflected the known historical usage of these pesticides. No correlation between the concentrations of pesticides and soil organic matter content or clay content can be found. The factors affecting residue levels and compositions of DDT and HCH were discussed. The contour maps of $\beta / \gamma$ ratios and DDT/ DDE ratios for both the shallow subsurface and deep layer soils were drawn.
\end{abstract}

(C) 2005 Elsevier Ltd. All rights reserved.

Keywords: DDT; HCH; Soil residues; Spatial distribution; Beijing outskirts

\section{Introduction}

Organochlorine pesticides (OCPs) are of worldwide concerns because of their persistence (Dimond and Owen, 1996), bioaccumulation (Nakata et al., 2002), and toxicity to human and other animal and plant lives (Jones and de Voogt, 1999). 1,1,1-Trichloro-2,2-bis-( $p$ chlorophenyl) ethane (DDT) and 1,2,3,4,5,6-hexachlorocyclohexane $(\mathrm{HCH})$ have been among the most widely used OCPs throughout the world. DDT was listed on the Stockholm Convention as one of 12 persistent or-

\footnotetext{
* Corresponding author. Tel.: +86106291 9177; fax: +8610 82521355.

E-mail address: xuxb@public.bta.net.cn (X. Xu).
}

ganic pollutants (POPs). The origin and fate of OCPs in soils with different land use have been extensively studied in many countries. Although the usage of OCPs was phased out for decades, the elevated concentrations were still observed in many agricultural soils (Szeto and Price, 1991; Harris et al., 2000) and the relationship between sites of greatest application and current residue levels was found strong (Shivaramaiah et al., 2002). The release of OCPs from soils continues to be a source to the environment (Munn and Gruber, 1997; Meijer et al., 2003).

Technical HCH and DDT consist of about $50 \%$ of pesticide products in the 1970s (Zhang, 1996) and were heavily used for agricultural purposes in the Beijing area. From 1972 to 1974, 208.5 tonnes of $\mathrm{HCH}$ and 52.2 tonnes of DDT were sold annually in the eastern suburbs of Beijing, 399.3 tonnes of $\mathrm{HCH}$ and 98.7 
tonnes of DDT in the western suburbs, and 2.25 tonnes of $\mathrm{HCH}$ and 39.59 tonnes of DDT in the remaining areas. An earlier survey has reported $\mathrm{HCHs}$ and DDTs residues to range from 22.0 to $254.0 \mathrm{ng} / \mathrm{g} \mathrm{dw}$ (mean $107.4 \mathrm{ng} / \mathrm{g}$ ) and from 2.0 to $175.0 \mathrm{ng} / \mathrm{g} \mathrm{dw}$ (mean $44.8 \mathrm{ng} / \mathrm{g}$ ), respectively, in wheat fields and those in orchard soils were generally in the range of 48 to $1375 \mathrm{ng} / \mathrm{g}$ and 1000 to $2000 \mathrm{ng} / \mathrm{g}$, respectively. $\mathrm{HCH}$ and DDT were used in limited amounts in orchard soils in the late $1970 \mathrm{~s}$ and applied at $22.5 \mathrm{~kg} \mathrm{ha}^{-1}$ in wheat fields before harvest every year (Cooperation group, 1980). The usage of technical HCH and DDT was banned in 1983 in China.

In the past two decades, there is little information on whether these agrochemicals accumulate in soils in Beijing, and, if they do, to what extent. Recently, systematic investigations have been carried out in soils from the outskirts of Beijing to assess the soil quality in the Beijing area. This paper presents the current status of OCPs residues. The dataset generated will serve as a baseline for further studies.

\section{Materials and methods}

\subsection{Sample collection}

This was an intensive soil-sampling program. The sampling area was $1100 \mathrm{~km}^{2}: 5 \mathrm{~km}$ east, $14 \mathrm{~km}$ south, $7 \mathrm{~km}$ west, and $6 \mathrm{~km}$ north from Beijing's fourth-ring road. The shallow subsurface soil samples $(5-30 \mathrm{~cm}$ depth) were collected every $1 \mathrm{~km}$, and 16 cores were pooled to obtain one representative sample for every $16 \mathrm{~km}^{2}$ area. The deep layer soil samples $(150-180 \mathrm{~cm}$ depth) were collected every $16 \mathrm{~km}^{2}$ area. The map of soil survey and sampling sites in the Beijing outskirts is shown in Fig. 1. Together, 47 shallow subsurface soil and 46 deep layer soil samples were analyzed. The soil samples are brown and mostly sandy loam and silt loam. Each fully mixed sample was air dried under a hood at room temperature and sieved to pass 35 mesh sieve. All samples were placed into amber glass bottles and refrigerated at $-4{ }^{\circ} \mathrm{C}$ until analysis.

\subsection{Extraction and cleanup}

All solvents obtained from the Beijing Chemical Factory were of analytical grade and were redistilled in allglass system before use. The reference standard mixtures of eight OCPs at a concentration of $100 \mathrm{mg} / \mathrm{l}$ were purchased from National Research Center for Certified Reference Materials, China. Florisil (Aldrich, USA) was activated for $16 \mathrm{~h}$ at $130^{\circ} \mathrm{C}$ and kept in a desiccator before use. 2,4,5,6-Tetrachloro- $m$-xylene was used as the surrogate standard (Supelco, Bellefonte, PA, USA).

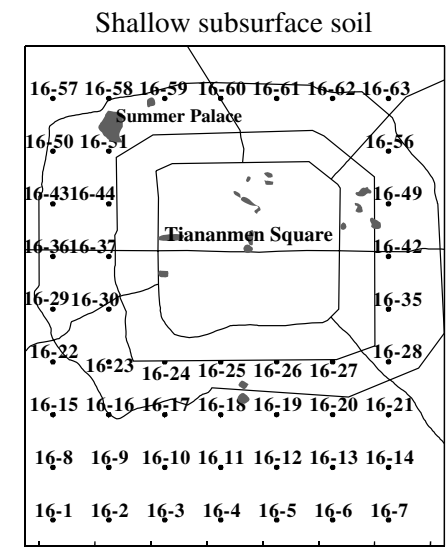
A. The third-ring road;
B. The fourth-ring road;
C. The fifth-ring road;
D. The Badaling highway;
E. Beijing airport express;
F. Jingjingtang highway;
G. Jingshi highway.

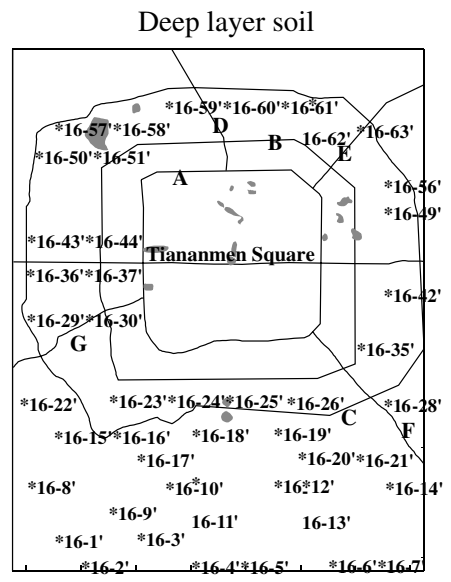

Fig. 1. Map of soil survey and sampling sites from the outskirts of Beijing. Forty seven shallow subsurface soil and 46 deep layer soil sampling sites are indicated.

An aliquot (5 g) of soil sample was weighed accurately and ground with $5 \mathrm{~g}$ anhydrous sodium sulfate. One milliliter of 2,4,5,6-tetrachloro- $m$-xylene at the concentration of $0.04 \mu \mathrm{g} / \mathrm{ml}$ was added. The mixtures were extracted with petroleum ether/acetone, $1 / 1(\mathrm{v} / \mathrm{v})$, by ultrasonication for $3 \mathrm{~min}$ and then centrifuged. This procedure was repeated three times. The extracts were combined and the solvent was reduced to about $1 \mathrm{ml}$ by using a $\mathrm{K}-\mathrm{D}$ concentrator in a water bath.

For isolation of OCPs, $5 \mathrm{~g}$ of activated Florisil was packed into a glass column $(33 \mathrm{~cm} \times 1 \mathrm{~cm}$ i.d.) with petroleum ether, covered with $2 \mathrm{~g}$ of anhydrous $\mathrm{Na}_{2} \mathrm{SO}_{4}$ at the top. The sample was loaded onto the column and eluted with $60 \mathrm{ml}$ of petroleum ether/ether (91/9) to obtain OCPs fraction. The fraction was concentrated by using a $\mathrm{K}-\mathrm{D}$ concentrator in a water bath and finally under a gentle stream of nitrogen to $0.2 \mathrm{ml}$.

Quantitative analysis of OCPs was carried out using an Agilent 6890 gas chromatograph equipped with a 
$\mathrm{Ni}^{63}$ electron capture detector and a HP-5 column ( $25 \mathrm{~m} \times 0.25 \mathrm{~mm}$ i.d., and $0.25 \mu \mathrm{m}$ film thickness) with ultrapure nitrogen as carrier gas and make-up gas. GC conditions were: injector and detector temperature 275 and $300{ }^{\circ} \mathrm{C}$, respectively, initial oven temperature $80^{\circ} \mathrm{C}$ held for $1 \mathrm{~min}$, increased at the rate of $10^{\circ} \mathrm{C} /$ min to $150^{\circ}$ and then ramped at $4{ }^{\circ} \mathrm{C} / \mathrm{min}$ to $280^{\circ} \mathrm{C}$ and held for $10 \mathrm{~min}$. A $1 \mu \mathrm{l}$ of the sample was injected in the splitless mode and the purge valve was opened at $0.75 \mathrm{~min}$. Compounds were identified by retention time using external standards and quantified using peak area integration.

Selected samples were re-analyzed by a Hewlett Packard 6890 GC coupled to a 5973 MSD operated in the selected ion monitoring mode to further confirm the identification of compounds. A DB-5 MS $(25 \mathrm{~m} \times 0.25$ $\mathrm{mm}$ i.d., $0.25 \mu \mathrm{m}$ film thickness) capillary column was used. The GC oven temperature program was as described above. The transfer line and quadrupole temperatures were 250 and $150^{\circ} \mathrm{C}$, respectively. Helium was used as carrier gas. Data acquisition and processing were controlled by a HP Chem-Station data system.

For quality assurance and quality control, the procedural blanks, matrixes spiked by the standard solution were analyzed. None of the target compounds were detected in the procedural blanks. The recoveries corrected by the surrogate from the soils ranged from $105.99 \pm 7.44 \%$ for $\alpha-\mathrm{HCH}$ to $11,8.58 \pm 7.27 \%$ for $\gamma$ $\mathrm{HCH}$. The detection limits of the method were in the range of $0.014 \mathrm{ng} / \mathrm{g}$ for $p, p^{\prime}$-DDE to $0.094 \mathrm{ng} / \mathrm{g}$ for $o, p^{\prime}$-DDD. All concentrations were expressed on a soil dry weight basis.

\section{Results}

The range, mean and median concentrations of the OCPs concentrations and selected soil properties are shown in Table 1. The concentrations of total $\mathrm{HCHs}$ in the shallow subsurface soils ranged from 1.36 to $56.61 \mathrm{ng} / \mathrm{g}$ with a median value of $5.25 \mathrm{ng} / \mathrm{g}$, while the total DDTs residue levels spanned several orders of magnitude, ranging from $0.77 \mathrm{ng} / \mathrm{g}$ to $2180 \mathrm{ng} / \mathrm{g} \mathrm{dw}$ with a median value of $38.66 \mathrm{ng} / \mathrm{g}$. The frequency distribution of DDTs residues in the shallow subsurface soils is approximately log normal. According to National Environmental Quality standards for Soils of China (GB15618-95), 46 out of 47 shallow subsurface soils, total $\mathrm{HCHs}$ values were lower than the first grade $(50 \mathrm{ng} / \mathrm{g})$, while for total DDTs, the concentrations in 26 samples were lower than the first grade $(50 \mathrm{ng} / \mathrm{g})$, and those in 18 samples were between the first and the second grade $(500 \mathrm{ng} / \mathrm{g})$, and those in two samples exceeded the third grade $(1000 \mathrm{ng} / \mathrm{g})$, respectively. The concentrations of total $\mathrm{HCHs}$ and total DDTs in the deep layer soils ranged from 0.40 to $5.36 \mathrm{ng} / \mathrm{g}$ (median
$0.99 \mathrm{ng} / \mathrm{g}$ ), and from 0.13 to $66.98 \mathrm{ng} / \mathrm{g}$ (median $0.82 \mathrm{ng} / \mathrm{g}$ ), respectively, and the total DDTs levels in 43 samples and $\mathrm{HCHs}$ levels in all samples were lower than the first grade.

There are very interesting and pioneering studies of DDT and $\mathrm{HCH}$ levels in soils from tropical and subtropical Asian countries. The mean values of DDT concentration in soil samples from Vietnam, Taiwan and Thailand were 110, 20 and $8.3 \mathrm{ng} / \mathrm{g}$, respectively, while those for $\mathrm{HCH}$ were $4.8,1.4$ and $0.4 \mathrm{ng} / \mathrm{g}$, respectively (Thao et al., 1993). The DDTs and HCHs levels were in the range of 4.3-2400 and $0.36-110 \mathrm{ng} / \mathrm{g}$ in Poland soils, respectively (Falandysz et al., 2001), and the total DDTs ranged from nondetectable to $11,800 \mathrm{ng} / \mathrm{g}$ with a geometrical mean of $9.63 \mathrm{ng} / \mathrm{g}$ in US soils (Aigner et al., 1998). In comparison with residual levels in archived background soils without any direct applications of pesticides in UK (0.1-10 ng/g; Meijer et al., 2001), in pristine areas such as Tibet plateau (DDTs: n.d.-2.83 ng/g; HCHs: $0.18-5.38 \mathrm{ng} / \mathrm{g}$; Fu et al., 2001) and European high altitude mountains (DDTs: $1.7-13 \mathrm{ng} / \mathrm{g}$; HCHs: 0.08-0.49 ng/g; Grimalt et al., 2004), and in some sites with relatively low application in South Korea $(<3 \mathrm{ng} / \mathrm{g}$; Kim and Smith, 2001), these values were high. When compared with data reported several years ago or recent data from places where degradation and dissipation of OCPs were retarded, these values were low because of long-term weathering. The concentrations of DDTs in orchard soils from New Zealand (median: $1170 \mathrm{ng} / \mathrm{g}$; Gaw et al., 2003) were about 1-2 orders of magnitude higher than the values in our report.

The spatial distribution of HCHs (Fig. 2) and DDTs (Fig. 3) for both the shallow subsurface soils and deep layer soils was rather similar, with higher levels found at the east, west and northwest sites for both pesticides, reflecting the known historical usage in the region. Moreover, there was a $\mathrm{HCH}$ factory once located at the south part of the city; therefore, the relative high residue levels of $\mathrm{HCHs}$ in the shallow subsurface soils were detected in the south. Correlation of log-transformed concentrations of HCHs with those of DDTs exhibited high coefficients (shallow subsurface soils: $r^{2}=0.544$, $P<0.01$ ), indicating the similar application history of technical $\mathrm{HCH}$ and DDT. One location with the greatest DDTs concentration (16-22) was not included due to a suspected recent source, which is discussed below.

\section{Discussion}

\subsection{Factors affecting residue levels}

A number of factors appear to control the environmental fate and behavior of organochlorine pesticides. Residue levels of organochlorine pesticides are affected by application history, agricultural practices, soil phys- 
Table 1

The range, mean and median of organochlorine pesticides (ng/g dw) and selected soil properties

\begin{tabular}{|c|c|c|c|c|c|c|c|c|}
\hline & \multicolumn{4}{|c|}{ Shallow subsurface soil $(n=47)$} & \multicolumn{4}{|c|}{ Deep layer soil $(n=46)$} \\
\hline & Minimum & Maximum & Mean & Median & Minimum & Maximum & Mean & Median \\
\hline $\mathrm{OC}(\%)$ & 0.66 & 3.25 & 1.68 & 1.65 & 0.16 & 1.38 & 0.60 & 0.51 \\
\hline Clay $(\%)$ & 6.80 & 22.33 & 11.39 & 11.02 & 2.20 & 31.80 & 13.45 & 13.50 \\
\hline$\alpha-\mathrm{HCH}$ & 0.32 & 8.19 & 1.27 & 0.70 & 0.14 & 1.28 & 0.34 & 0.29 \\
\hline$\beta-\mathrm{HCH}$ & 0.37 & 45.11 & 5.69 & 2.70 & n.d. ${ }^{\mathrm{a}}$ & 3.99 & 0.60 & 0.26 \\
\hline$\gamma-\mathrm{HCH}$ & n.d. & 12.86 & 2.45 & 0.86 & 0.20 & 1.03 & 0.47 & 0.40 \\
\hline$\delta-\mathrm{HCH}$ & n.d. & 5.85 & 0.94 & 0.43 & n.d. & 0.61 & 0.10 & 0.07 \\
\hline $\mathrm{HCHs}^{\mathrm{b}}$ & 1.36 & 56.61 & 10.35 & 5.25 & 0.40 & 5.36 & 1.51 & 0.99 \\
\hline$\beta / \gamma$ & 0.09 & 29.47 & 3.96 & 2.30 & n.d. & 7.78 & 1.22 & 0.52 \\
\hline$p, p^{\prime}-\mathrm{DDE}$ & 0.22 & 832.37 & 51.07 & 16.88 & 0.05 & 48.42 & 1.97 & 0.22 \\
\hline$p, p^{\prime}$-DDD & 0.15 & 50.38 & 13.31 & 3.06 & n.d. & 10.18 & 0.69 & 0.17 \\
\hline$o, p^{\prime}$-DDT & n.d. & 533.23 & 19.20 & 3.28 & n.d. & 4.46 & 0.32 & 0.12 \\
\hline$p, p^{\prime}$-DDT & n.d. & 1924.76 & 57.21 & 6.72 & n.d. & 50.39 & 2.61 & 0.13 \\
\hline $\mathrm{DDTs}^{\mathrm{c}}$ & 0.77 & 2178.55 & 140.79 & 38.66 & 0.13 & 66.98 & 5.59 & 0.82 \\
\hline DDT/DDE & 0.006 & 63.9 & 2.00 & 0.38 & 0.05 & 231.9 & 8.30 & 0.86 \\
\hline
\end{tabular}

\footnotetext{
a Nondetectable.

b Sum of $\mathrm{HCH}$ isomers.

${ }^{\mathrm{c}}$ Sum of DDT isomers and metabolites.
}
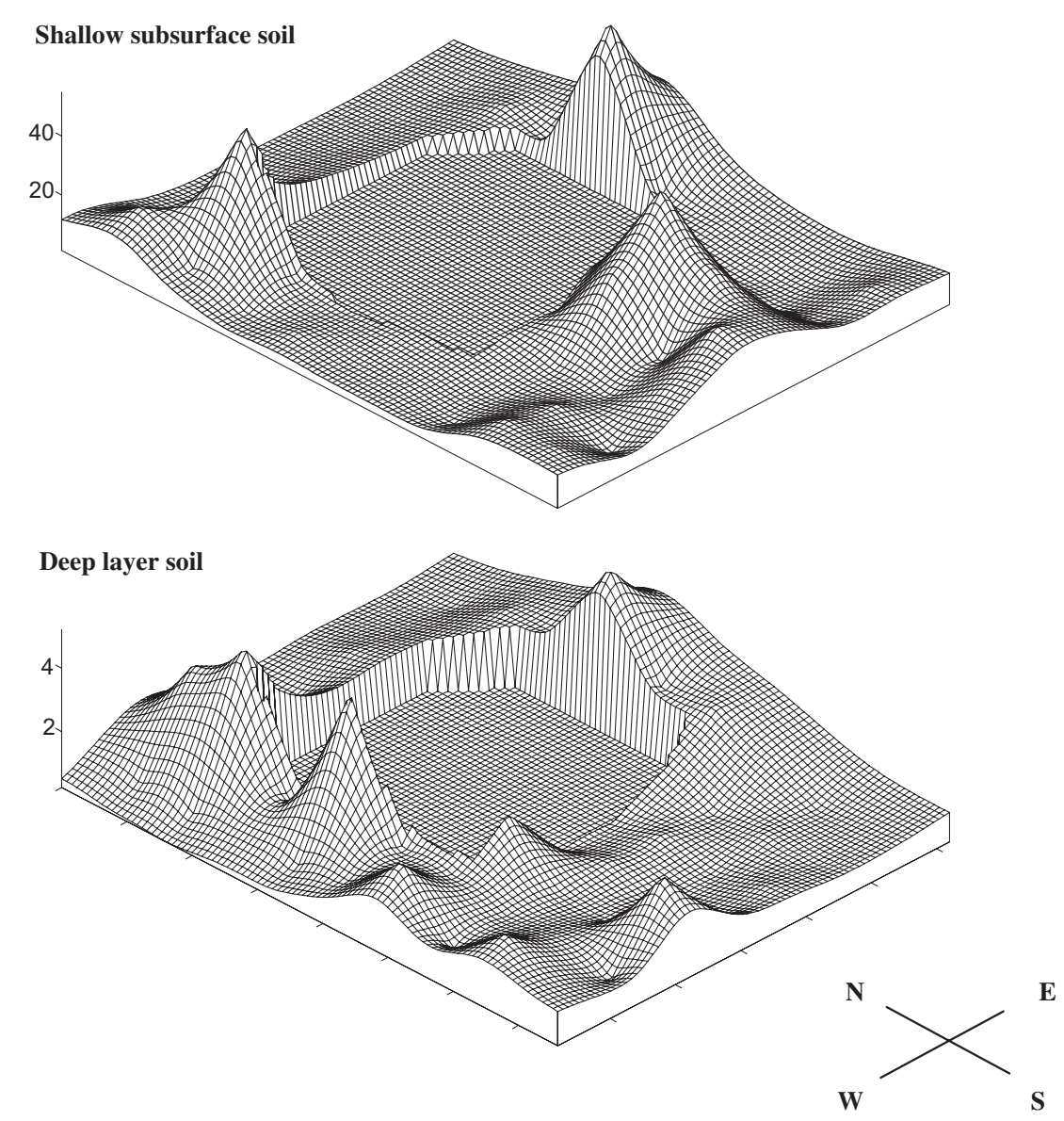

Fig. 2. The spatial distribution of HCHs in soils from the outskirts of Beijing. 

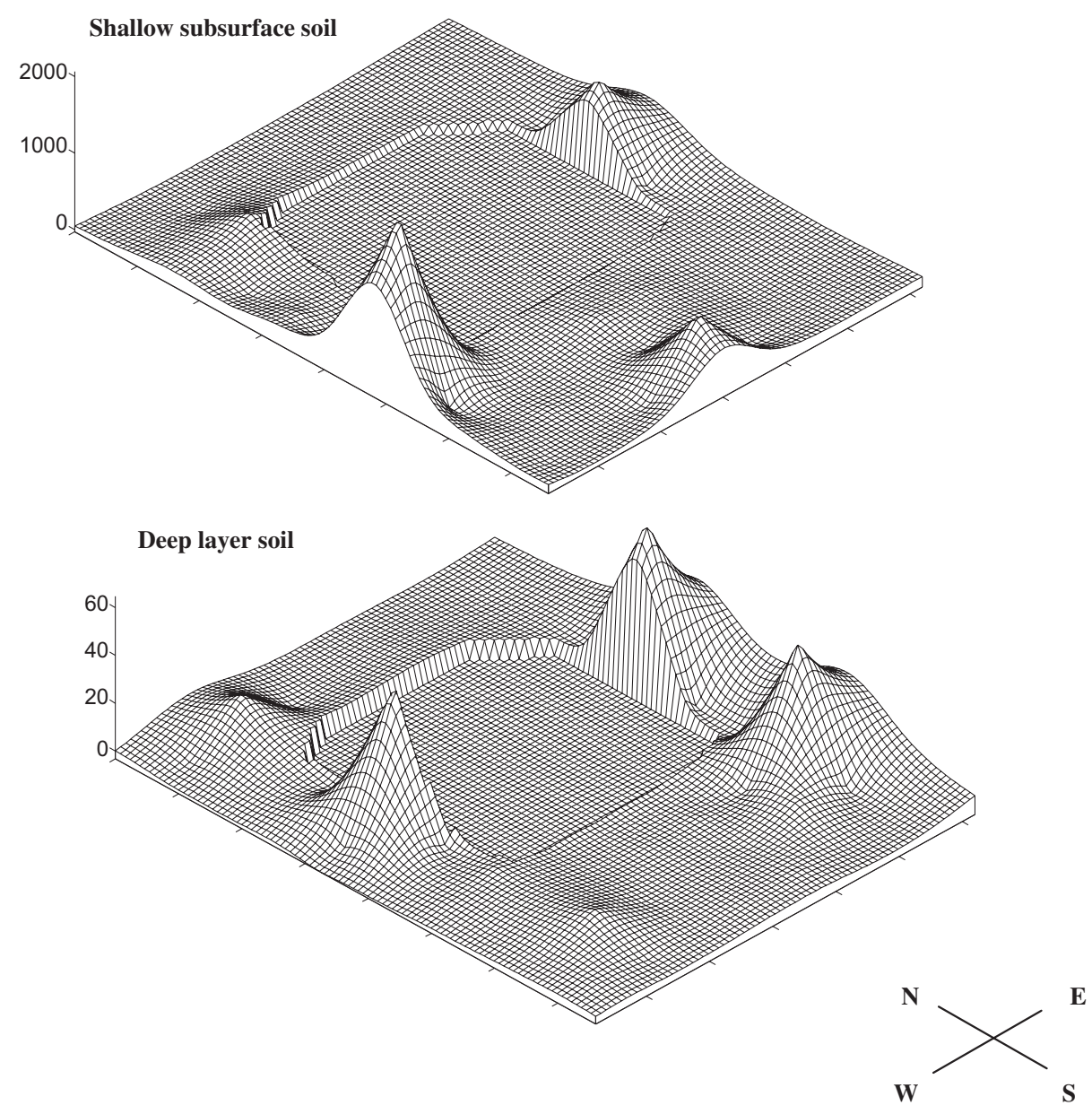

Fig. 3. The spatial distribution of DDTs in soils from the outskirts of Beijing.

ico-chemical properties, as well as physico-chemical properties of agrochemicals and meteorological factors such as temperature and rainfall etc. (Szeto and Price, 1991; Boul et al., 1994; Spencer et al., 1996).

OCPs are hydrophobic and considered to be easily adsorbed by soil organic matter. A study carried out in mountain soils from the subtropical Atlantic (Teide, Tenerife Island) found that DDTs and HCHs exhibited a high dependence on soil total organic carbon (Ribes and Grimalt, 2002). However, in our present study, no correlation between the concentrations and soil organic carbon content was found, indicating that residue levels were a reflection of OCPs application history and dissipation rates rather than air-soil equilibrium, which is similar to agricultural soils from Alabama (Harner et al., 1999) and from Georgia and South Carolina (Kannan et al., 2003). Residues of OCPs dissipated in loamy sand much faster than in the muck and higher levels of OCPs were often detected in the muck (DDTs: 3997 ng/g, Szeto and Price, 1991; 11,800 ng/g, Aigner et al., 1998). However, in our study, Sample Nos. 1622 , in which the highest DDTs was found $(2178 \mathrm{ng} / \mathrm{g})$, had both the soil organic carbon content $(1.01 \%)$ and the clay content $(7.03 \%)$ lower than the median values.

OCP residues have been studied in different soil horizons (Boul et al., 1994; Miglioranza et al., 1999; Weiss, 2000; Feng et al., 2003), and much attention was paid to the shallow subsurface soils. There are very limited data available for the deep soil layers, which is an indicator of potentiality of OCPs present in the groundwater contamination. In our study, the concentrations of HCHs and DDTs in the deep layer soils $(150-180 \mathrm{~cm}$ depth) were about an order of magnitude lower than those in the shallow subsurface soils, because of mechanical mixing and irrigation in the agricultural soils as well as long-term leaching.

Fields with crops that require higher OCPs use usually contain higher residue levels even after long-term weathering. Our shallow subsurface soil samples were pooled from 16 soil cores with different land uses, and 
it was very difficult to assess the effect of different land use on soil residues of OCPs. As for the deep layer soils, the highest concentrations of $p, p^{\prime}$-DDE (range: $0.12-$ $2.26 \mathrm{ng} / \mathrm{g}$; median: $1.26 \mathrm{ng} / \mathrm{g}$ ) were found in orchard soils among wheat fields (range: $0.06-0.69 \mathrm{ng} / \mathrm{g}$; median: $0.17 \mathrm{ng} / \mathrm{g}$ ), vegetable gardens (range: $0.09-2.24 \mathrm{ng} / \mathrm{g}$; median: $0.17 \mathrm{ng} / \mathrm{g}$ ), wood soils (range: $0.07-1.87 \mathrm{ng} / \mathrm{g}$; median: $0.19 \mathrm{ng} / \mathrm{g}$ ), and maize fields (median: 0.05$0.21 \mathrm{ng} / \mathrm{g}$; median: $0.16 \mathrm{ng} / \mathrm{g}$ ). No significant difference was found for $\mathrm{HCH}$ isomers. The results are consistent with the application history of OCPs (Cooperation group, 1980).

Beijing is located in the temperate region. It is cold and dry in winter with the lowest temperature of $-15.4{ }^{\circ} \mathrm{C}$, while in summer it is hot and humid with the highest temperature of $38^{\circ} \mathrm{C}$. Mean yearly precipitation is about $630 \mathrm{~mm}$. The persistence of OCPs in soil is greater in temperate climates compared to the tropics (Iwata et al., 1994).

\subsection{Compositions of $O C$ residues}

Technical HCH mixtures containing $\alpha-(67 \%), \beta-$ $(10 \%), \gamma-(15 \%), \delta-(8 \%) \mathrm{HCH}$ had been used in China. $\beta-\mathrm{HCH}$ has all chlorines in equatorial positions and the lowest vapor pressure. It is the most persistent isomer and tends to accumulate in soil ( $\mathrm{Li}, 1999)$. The mean percentages of $\mathrm{HCH}$ isomers in the shallow subsurface soils were as follows: $\beta>\gamma>\alpha>\delta$, which confirmed that the technical $\mathrm{HCH}$ had not been in use in the Beijing area for quiet a long time, while those in the deep
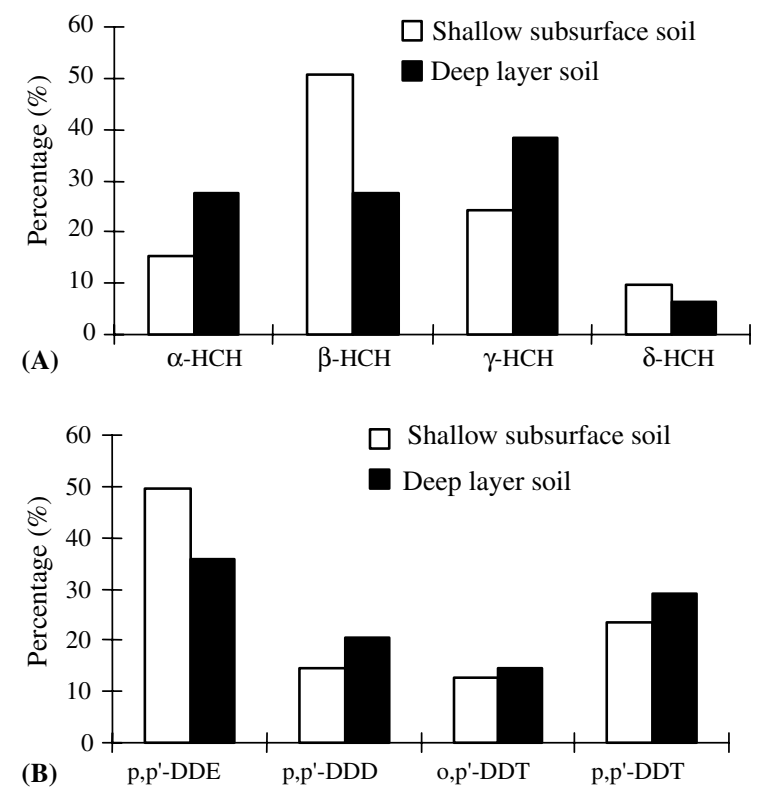

Fig. 4. Percentage of (A) HCH isomers and (B) DDT isomers and metabolites in the shallow subsurface and deep layer soils. layer soils were: $\gamma>\alpha \approx \beta>\delta$ (Fig. 4A), indicating that $\gamma-\mathrm{HCH}$ and $\alpha-\mathrm{HCH}$ had the higher leaching ability than $\beta-\mathrm{HCH}$ and $\delta-\mathrm{HCH}$ (Cooperation group, 1980). The ratios of $\beta-\mathrm{HCH}$ to $\gamma$-isomer have been used in this study to indicate historical use and trace pollution sources. Forty five out of 47 shallow subsurface soils had $\beta / \gamma$ ratios ranging from 0.09 to 29.47 with a median of 2.30 . As for the deep layer soils, the $\beta / \gamma$ ratios were in the range of n.d. to 7.78 with a median of 0.52 , lower than those of the shallow subsurface soils because of $\gamma-\mathrm{HCH}$ being readily leached into the soil (Simonich and Hites, 1995; Miglioranza et al., 1999). The contour maps of the ratios of $\beta / \gamma$ isomers provide a clear overview of the proportions of two $\mathrm{HCH}$ isomers in the studied area (Fig. 5). The greatest values for both shallow subsurface soils and deep layer soils were located at the northwest sites where high total $\mathrm{HCH}$ were also observed.

Technical DDT is typically composed of $77.1 \%$ $p, p^{\prime}$-DDT, $14.9 \% o, p^{\prime}$-DDT, $4 \% p, p^{\prime}$-DDE, and some other trace impurities. The mean percentages of individual compounds in both shallow subsurface soils and deep layer soils were as follows: $p, p^{\prime}-\mathrm{DDE}>p, p^{\prime}-\mathrm{DDT}>$ $p, p^{\prime}$-DDD $>o, p^{\prime}$-DDT (Fig. 4B). The mean percentage of $p, p^{\prime}$-DDE in the deep layer soils was lower than that in the shallow subsurface soils, but that of $p, p^{\prime}$-DDD was higher, because DDT is likely to be dechlorinated to DDD in the anaerobic condition in the deep layer soils. It has been suggested that $o, p^{\prime}$-DDT and $p, p^{\prime}$-DDT have declined at similar rates in Alabama, USA soils (Harner et al., 1999). However, in our present study, the median values of $o, p^{\prime} / p, p^{\prime}$-isomers are 1:2.5 and 1:1.3 for the shallow subsurface soils and deep layer soils, respectively, which are different from its "starting" value of 1:5.2.

The ratio of parent compound to metabolites was used to infer sources and qualitatively judge the age of contaminant residues in soil. DDT/DDE ratios were quite variable, ranging from 0.006 to 63.9 with a median of 0.38 for the shallow subsurface soils, and from 0.05 to 231.9 with a median of 0.86 for the deep layer soils. Most soils contained more DDE than DDT, indicating DDT residues are from "old" sources. The contour maps (Fig. 6) showed that highest DDT/DDE ratios for the shallow subsurface soils and deep layer soils were located at the southwest and southeast sites, respectively, where high DDTs levels were found. Extremely high ratios were found in the deep layer soils, probably because of the long-term leaching of $p, p^{\prime}$-DDT and retarded degradation of DDT to DDE in the deep layer soils (Miglioranza et al., 1999; Harris et al., 2000). Great proportions of $p, p^{\prime}$-DDT were also observed in agricultural soils of central Germany (Manz et al., 2001) and of southern Ontario (Meijer et al., 2003), and in some western USA soils (Hitch and Day, 1992). It was found that high copper (Van Zwieten et al., 2003) or arsenic (Gaw et al., 2003) content could inhibit the degradation of 

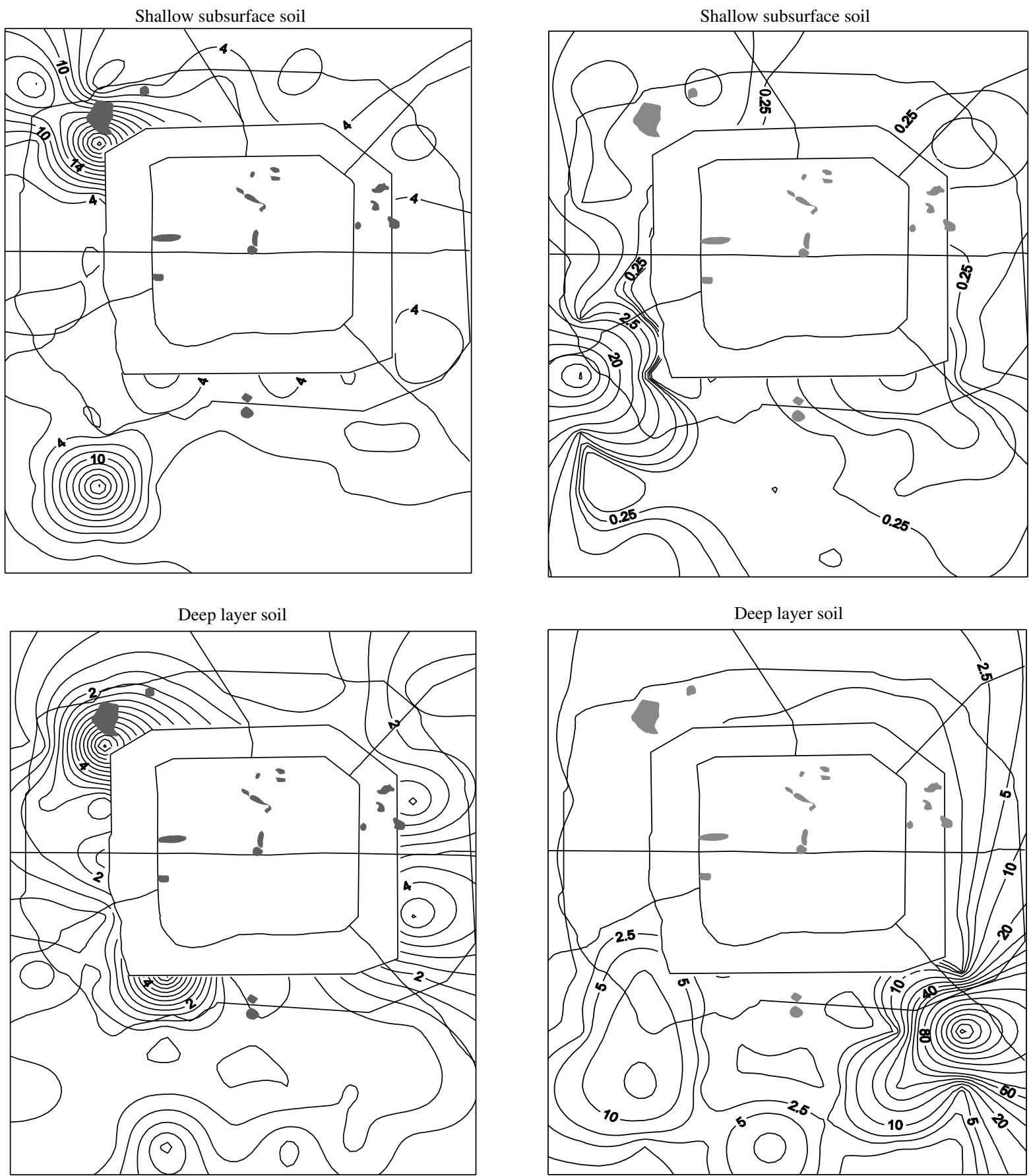

Fig. 5. The contour maps of $\beta / \gamma$ ratios.

DDT to DDE in soil. However, the total metal contents (data provided by Professor H.X. Cheng) including copper and arsenic in the shallow subsurface soils were generally at the same levels, no correlation between DDT/ DDE ratios and metal contents can be found. Another
Fig. 6. The contour maps of DDT/DDE ratios.

study carried out in Beijing reported that accumulative levels of DDT in the mother's milk declined irregularly, and the authors suggested that this might result from the possible use of dicofol which contains $5-10 \%$ DDT as impurity (Yu et al., 2001). Dicofol is classed as organo- 
chlorine pesticides, and DDT is one of the intermediate products during its manufacture. Now the use of dicofol was restricted in China because relatively high levels of DDT contamination were found in soils where dicofol was applied.

\section{Conclusions}

The usage of the technical HCH and DDT has been illegal for decades in China, and OCPs residues in most sites were relatively low. The residual levels in the deep layer soils were an order of magnitude lower than those in the shallow subsurface soils. The spatial distributions of HCHs and DDTs in the outskirts of Beijing were quite similar, which reflected the known historical usage. No correlation of residue levels with soil organic carbon content and clay content was found, indicating that the soil-air system was out of equilibrium. In some typical sites, the relative high residue levels of DDTs were observed, which may result from a combination of heavy historical use and retarded degradation of DDT in soils. Moreover, it was quite possible that dicofol may be a "new" source, which remains to be further studied.

\section{Acknowledgments}

This project was supported by the Ministry of Science and Technology of China ("973" Project No. G1999045707). We thank the Agilent Company for providing experimental facilities and Xiufeng Liu, Huiming. Chen, Wenjian Lao, and Xuetong Wang for technical assistance. We are very grateful to Prof. Zheming Ni and Shaogang Chu for reviewing this manuscript.

\section{References}

Aigner, E.J., Leone, A.D., Falconer, R.L., 1998. Concentrations and enantiomeric ratios of organochlorine pesticides in soils from the US Corn Belt. Environ. Sci. Technol. 32, 1162-1168.

Boul, H.L., Garnham, M.L., Hucker, D., Baird, D., Aislabie, J., 1994. Influence of agricultural practices on the levels of DDT and its residues in soil. Environ. Sci. Technol. 28, 1397-1402.

Cooperation group, 1980. Studies on pollution investigation and prevention measures in Beijing southeast suburbs [Collection] (1976-1979).

Dimond, J.B., Owen, R.B., 1996. Long-term residue of DDT compounds in forest soils in Maine. Environ. Pollut. 92, $1122-1130$.

Falandysz, J., Brudnowska, B., Kawano, M., Wakimoto, T., 2001. Polychlorinated biphenyls and organochlorine pesticides in soils from the southern part of Poland. Arch. Environ. Contam. Toxicol. 40, 173-178.
Feng, K., Yu, B.Y., Ge, D.M., Wong, M.H., Wang, X.C., Cao, Z.H., 2003. Organo-chlorine pesticide (DDT and $\mathrm{HCH}$ ) residues in the Taihu Lake Region and its movement in soilwater system I. Field survey of DDT and $\mathrm{HCH}$ residues in ecosystem of the region. Chemosphere 50, 683-687.

Fu, S., Chu, S.G., Xu, X.B., 2001. Organochlorine pesticide residue in soils from Tibet, China. Bull. Environ. Contam. Toxicol. 66, 171-177.

Gaw, S.K., Palmer, G., Kim, N.D., Wilkins, A.L., 2003. Preliminary evidence that copper inhibits the degradation of DDT to DDE in pip and stonefruit orchard soils in the Auckland region, New Zealand. Environ. Pollut. 122, 1-5.

Grimalt, J.O., Van Drooge, B.L., Ribes, A., Vilanova, R.M., Fernandez, P., Appleby, P., 2004. Persistent organochlorine compounds in soils and sediments of European high altitude mountain lakes. Chemosphere 54, 1549-1561.

Harner, T., Wideman, J.L., Jantunen, L.M.M., Bidleman, T.F., Parkhurst, W.J., 1999. Residues of organochlorine pesticides in Alabama soils. Environ. Pollut. 106, 323-332.

Harris, M.L., Wilson, L.K., Elliott, J.E., Bishop, C.A., Tomlin, A.D., Henning, K.V., 2000. Transfer of DDT and metabolites from fruit orchard soils to American Robins (Turdus migratorius) twenty years after agricultural use of DDT in Canada. Arch. Environ. Contam. Toxicol. 39, 205-220.

Hitch, R.K., Day, H.P., 1992. Unusual persistence of DDT in some western USA soils. Bull. Environ. Contam. Toxicol. 48, 255-260.

Iwata, H., Tanabe, S., Sakai, N., Nishimura, A., Tatsukawa, R., 1994. Geographical distribution of persistent organochlorines in air, water and sediments from Asia and Oceania, and their implications for global redistribution from lower latitudes. Environ. Pollut. 85, 15-33.

Jones, K.C., de Voogt, P., 1999. Persistent organic pollutants (POPs): state of the science. Environ. Pollut. 100, 209-221.

Kannan, K., Battula, S., Loganathan, B.G., Hong, C.S., Lam, W.H., Villeneuve, D.L., Sajwan, K., Giesy, J.P., Aldous, K.M., 2003. Trace organic contaminants, including toxaphene and trifluralin, in cotton field soils from Georgia and South Carolina, USA. Arch. Environ. Contam. Toxicol. 45, 30-36.

Kim, J.-H., Smith, A., 2001. Distribution of organochlorine pesticides in soils from South Korea. Chemosphere 43, 137140.

Li, Y.F., 1999. Global technical hexachlorocyclohexane usage and its contamination consequences in the environment: from 1948 to 1997. Sci. Total Environ. 232, 121-158.

Manz, M., Wenzel, K.-D., Dietze, U., Schüürmann, G., 2001. Persistent organic pollutants in agricultural soils of central Germany. Sci. Total Environ. 277, 187-198.

Meijer, S.N., Halsall, C.J., Harner, T., Peters, A.J., Ockenden, W.A., Johnston, A.E., Jones, K.C., 2001. Organochlorine pesticides residues in archived UK soil. Environ. Sci. Technol. 35, 1989-1995.

Meijer, S.N., Shoeib, M., Jantunen, L.M., Jones, K.C., Harner, T., 2003. Air-soil exchange of organochlorine pesticides in agricultural soils. 1. Field measurements using a novel in situ sampling device. Environ. Sci. Technol. 35, 3315-3324.

Miglioranza, K.S.B., Aizpún de Moreno, J.E., Moreno, V.J., Osterrieth, M.L., Escalante, A.H., 1999. Fate of organochlorine pesticides in soils and terrestrial biota of "Los Padres" Pond watershed, Argentina. Environ. Pollut. 105, 91-99. 
Munn, M.D., Gruber, S.J., 1997. The relationship between land use and organochlorine compounds in streambed sediment and fish in the central Columbia plateau, Washington and Idaho, USA. Environ. Toxicol. Chem. 16, 1877-1887.

Nakata, H., Kawazoe, M., Arizono, K., Abe, S., Kitano, T., Shimada, H., Li, W., Ding, X., 2002. Organochlorine pesticides and polychlorinated biphenyl residues in foodstuffs and human tissues from China: status of contamination, historical trend, and human dietary exposure. Arch. Environ. Contam. Toxicol. 43, 473-480.

Ribes, A., Grimalt, J.O., 2002. Temperature and organic matter dependence of the distribution of organochlorine compounds in mountain soils from the subtropical Atlantic (Teide, Tenerife Island). Environ. Sci. Technol. 36, 821827.

Shivaramaiah, H.M., Odeh, I.O.A., Kennedy, I.R., Skerritt, J.H., 2002. Mapping the distribution of DDT residues as DDE in the soils of the irrigated regions of Northern New South Wales, Australia using ELISA and GIS. J. Agric. Food Chem. 50, 5360-5367.

Simonich, S.L., Hites, R.A., 1995. Organic pollutant accumulation in vegetation. Environ. Sci. Technol. 29, 2905-2914.
Spencer, W.F., Singh, G., Taylor, C.D., LeMart, R.A., Cliath, M.M., Farmer, W.J., 1996. DDT persistence and volatility as affected by management practices after 23 years. J. Environ. Qual. 35, 815-821.

Szeto, S.Y., Price, P.M., 1991. Persistence of pesticide residues in mineral and organic soils in the Fraser valley of British Columbia. J. Agric. Food Chem. 39, 1679-1684.

Thao, V.D., Kawano, M., Tatsukawa, R., 1993. Persistent organochlorine residues in soils from tropical and subtropical Asian countries. Environ. Pollut. 81, 61-71.

Van Zwieten, L., Ayres, M.R., Morris, S.G., 2003. Influence of arsenic co-contamination on DDT breakdown and microbial activity. Environ. Pollut. 124, 331-339.

Weiss, P., 2000. Vegetation/soil distribution of semi volatile organic compounds in relation to their physicochemical properties. Environ. Sci. Technol. 34, 1707-1714.

Yu, H.F., Zhao, X.D., Zhang, X.M., Zhu, Z.Q., Liu, J.L., 2001. Dynamic study on the accumulative levels of organochlorine pesticides in the mother' milk in Beijing. J. Environ. Health 18, 352-354 (in Chinese with English abstract).

Zhang, Z.M., 1996. The development of Chinese pesticide industry. Pesticides 35, 12-14 (in Chinese). 